\title{
Elucidating Effects of Orbital Delocalization on Electrochemiluminescent Efficiency for Carbon Nitrides
}

Yanfeng Fang, Yuhua Hou, Hong Yang, Wang Li, Jin Ma, Dan Han, Xuwen Cao, Songqin Liu, Yanfei Shen, Yuanjian Zhang*

Jiangsu Engineering Laboratory of Smart Carbon-Rich Materials and Device, Jiangsu Province Hi-Tech Key Laboratory for Bio-Medical Research, State Key Laboratory of

Bioelectronics, School of Chemistry and Chemical Engineering, Medical School, Southeast University, Nanjing 211189, China.

E-mail: Yuanjian.Zhang@seu.edu.cn 


\begin{abstract}
Electrochemiluminescence (ECL), an emission of light excited by electrochemical reactions, has drawn attention as tools across diverse fields, ranging from clinical disease diagnosis to photo-/electro-catalysts development. Nonetheless, the ECL efficiency of most luminophores in aqueous solutions is low, which significantly hamper their broad applications; thus, understanding the intrinsic factors for ECL efficiency is highly envisioned. Herein, taking emerging carbon nitride $(\mathrm{CN})$ with unique electronic structures and rigid 2D backbone as a model luminophore, we report that the orbital delocalization was a promising unifying factor for its ECL efficiency. Behind the complicated transformation of molecular structures regarding cyanoterminal groups and triazine/heptazine basal frameworks, the orbital delocalization of the as-prepared $\mathrm{CN}$ was found to be generally improved at an elevated condensation temperature. Such intrinsic evolution in electronic structure favored the electron injection in excitation and photon emission afterward in ECL of CN. As a result, the cathodic ECL efficiency of CN was remarkably improved to a new milestone of 170fold greater than benchmark $\mathrm{Ru}(\mathrm{bpy}){ }_{3} \mathrm{Cl}_{2}$.
\end{abstract}




\section{Introduction}

Highly efficient interconversion of different types of energy is essential not only in living but also for science and technology development. One prominent example is that chlorophyll, enzymes, and Escherichia coli maintain normal physiological function at an extreme efficiency approaching the physical limit. In contrast, there exists a giant gap for artificial devices to pursue. For instance, electrochemiluminescence (ECL), a light emission process in which excited species are generated at electrode surfaces by electrochemical reactions, has been widely applied ranging from clinical disease diagnosis to bioimaging. ${ }^{1-7}$ Nonetheless, ECL efficiency (number of generated photons per occupied electrons) of most emitters in aqueous solutions, including the commercialized benchmark tris(2,2'-bipyridyl)ruthenium(II) chloride ( $\left.\mathrm{Ru}(\mathrm{bpy})_{3} \mathrm{Cl}_{2}\right)$, is essentially low (typically less than $2 \%$ ), ${ }^{8}$ which significantly hamper their broad applications.

Numerous efforts have been devoted to addressing this problem, e.g., exploring new ECL emitters via screening luminophores with superior photophysical properties. ${ }^{7,}$ 9-14 Alternatively, the ECL efficiency of existing emitters was enhanced by strengthening intermolecular charger transfer, ${ }^{15-16}$ radical stabilization, ${ }^{17-20}$, and aggregation effects. ${ }^{13-}$ ${ }^{14,21-23}$ Despite these unprecedented successes, the study of ECL emitters with high ECL efficiency and the associated mechanism is still in infancy. For instance, the reliable correlations between photoluminescent (PL) quantum yield (QY) and ECL efficiency remain controversial, ${ }^{13,18,24}$ as the excitation kinetics of PL and ECL are different, e.g., the time scale of the former is faster than the latter by up to 6 orders of magnitude. Moreover, in previous studies, the ECL efficiency is often confused with ECL intensity, ${ }^{25}$ making the intrinsic comparison among different ECL emitters difficult. Therefore, from both a fundamental and application point of view, it is urgent to understand the intrinsic factors that influence ECL efficiency and consequently make an improvement. 
Due to the unique rigid 2D backbone and the associated electronic structures, polymeric carbon nitride $(\mathrm{CN})$ has emerged as a promising new generation of metalfree luminophore. ${ }^{26-29}$ It had demonstrated a record cathodic ECL efficiency of ca. seven times of benchmark $\mathrm{Ru}(\mathrm{bpy}){ }_{3} \mathrm{Cl}_{2}$ in an aqueous solution. ${ }^{30}$ Herein, taking $\mathrm{CN}$ with modulable molecular structures as a model system, we report the physicochemical insights of orbital delocalization on enhancing ECL efficiency by a general kinetic evaluation of electrons and photons participated-processes in ECL. In contrast to PL, it was disclosed that the quantitative orbital delocalization index (ODI), associated with the complicated development of cyano-terminal groups and basal triazine/heptazine frameworks during the thermal condensation of $\mathrm{CN}$, could be regarded as a unified intrinsic factor for $\Phi_{\mathrm{ECL}}$ of CN. Following this finding, the cathodic ECL efficiency of $\mathrm{CN}$ photoelectrode further improved remarkably up to ca. 170 times of benchmark $\mathrm{Ru}(\mathrm{bpy}){ }_{3} \mathrm{Cl}_{2}$.

\section{Results and Discussion}

Following our previous work, ${ }^{30}$ fluorine-doped tin oxide (FTO) was used as the substrate to absorb microwave energy, on which cyanamide could be rapidly heated and polymerized on FTO (Figure 1a). A thermal infrared camera was used to monitor the temperature distribution in real-time during the microwave-assisted synthesis (Figure 1b and S1). As shown in Movie S1, the temperature of the reaction system could quickly increase at ca. $60^{\circ} \mathrm{C} / \mathrm{s}$ by microwave irradiation. As a result, robust and uniform $\mathrm{CN}$ films under different temperatures were successfully grown on FTO in seconds, denoting $\mathrm{CN}_{\text {MWT }}\left(\mathrm{T}=400\right.$ to $720{ }^{\circ} \mathrm{C}$, see morphology, crystal structures, electronic structures, and chemical bonding of $\mathrm{CN}_{\mathrm{MWT}}$ in Figure S2-6). Notably, $\mathrm{CN}$ started to decompose at a temperature higher than $600{ }^{\circ} \mathrm{C}$ (see the thermal image and TGA curves in Figure S1e and S7).

The detailed chemical structure of different $\mathrm{CN}_{\mathrm{MWT}}$ was investigated by Fourier transformed infrared spectroscopy (FT-IR). As shown in Figure 1c, the FT-IR spectra of all $\mathrm{CN}_{\mathrm{MWT}}$ showed the peak at around 800 and $1100-1700 \mathrm{~cm}^{-1}$, typically attributing 
to triazine or heptazine ring out of plane bending and the $\mathrm{C}-\mathrm{N}$ heterocycles stretching vibrations, respectively. ${ }^{31-32}$ Notably, characteristic vibrations for $v\left(-\mathrm{NH}_{2}\right)$ at $3457 / 3325 \mathrm{~cm}^{-1}$ and $\mathrm{C} \equiv \mathrm{N}$ at $2205 \mathrm{~cm}^{-1}$ were observed for $\mathrm{CN}_{\mathrm{MW} 400},{ }^{33-34}$ suggesting an incomplete polymerization; at the higher temperature, these terminal groups gradually disappeared.

(a)

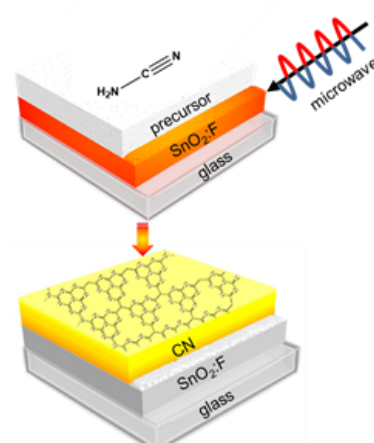

(b)

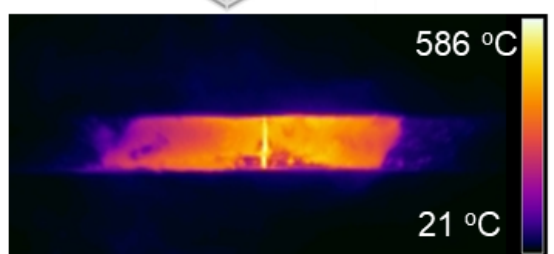

(c)

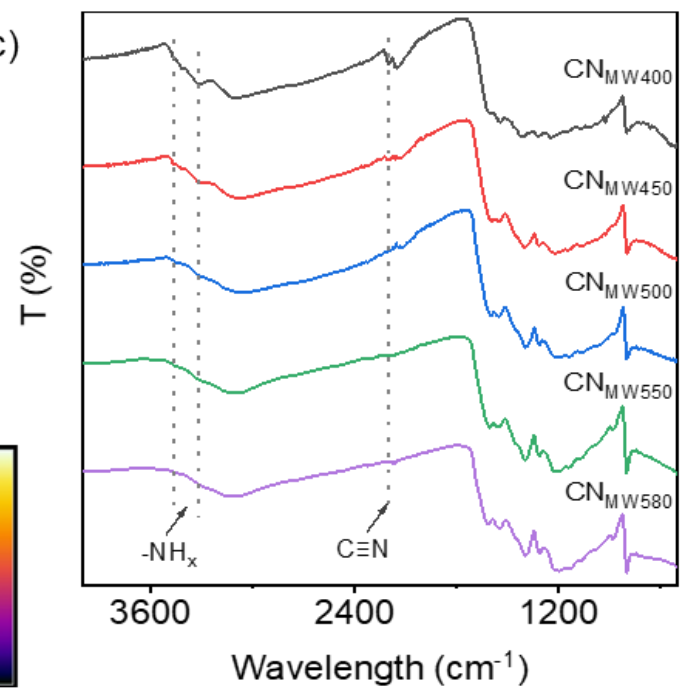

(d)

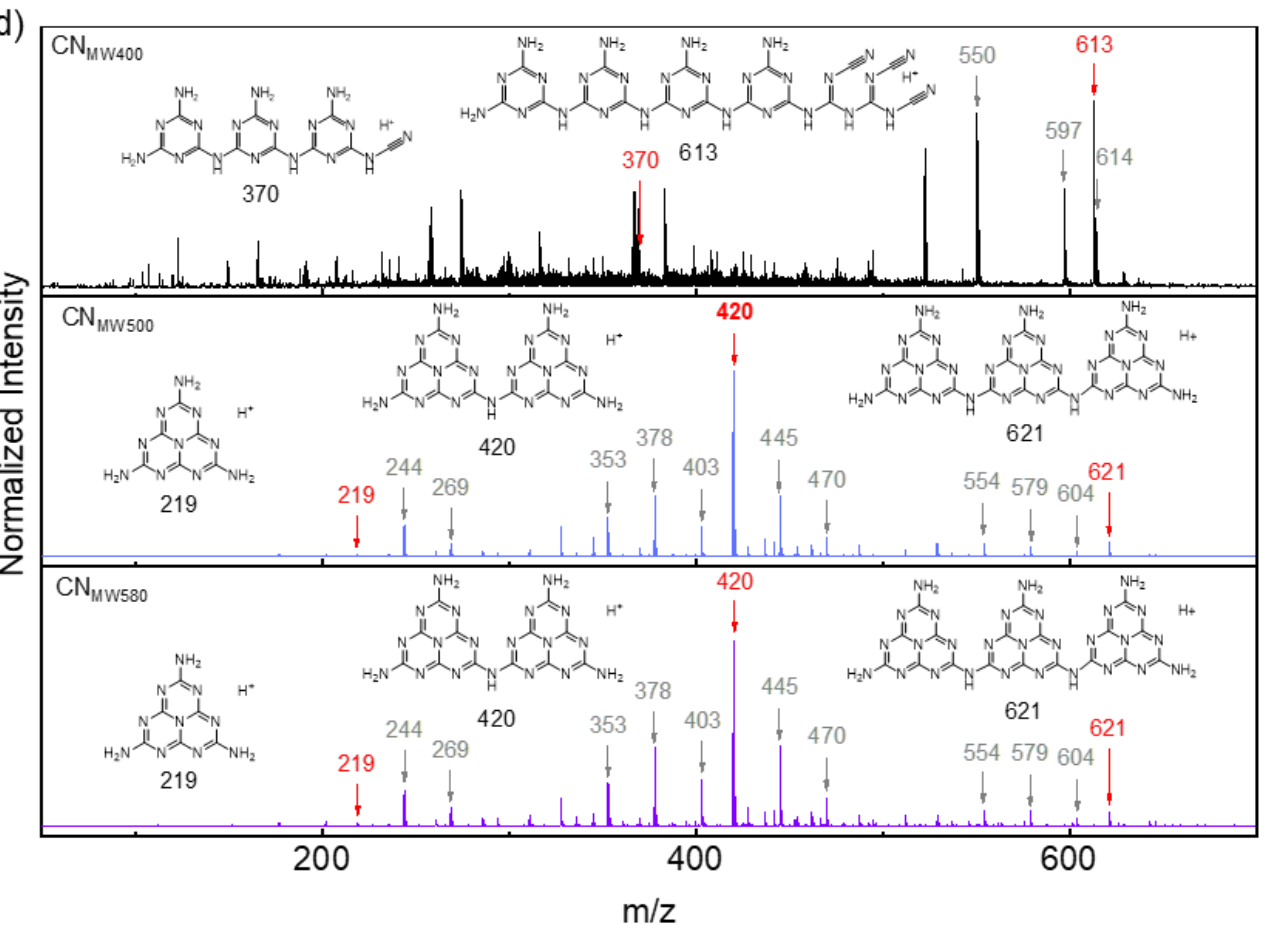

Figure 1. (a) Scheme of microwave-assisted synthesis of $\mathrm{CN}$ photoelectrode. (b) Thermal image for temperature distributions of $\mathrm{CN}_{\mathrm{MW} 580}$ on FTO by microwave heating. (c) FT-IR and (d) LDI-TOF mass spectra of $\mathrm{CN}_{\mathrm{MWT}}$ ( $\mathrm{T}=400$ to $580{ }^{\circ} \mathrm{C}$ ) 
To disclose more precise evolution of molecular structures, especially for the exact type of repeating units, during the condensation synthesis of $\mathrm{CN}_{\mathrm{MWT}}$, the matrix-free laser desorption/ionization time-of-flight (LDI-TOF) mass spectra of $\mathrm{CN}_{\mathrm{MW} 400 \text {, }}$ $\mathrm{CN}_{\mathrm{MW} 500}, \mathrm{CN}_{\mathrm{Mw} 580}$ (Figure 1d) and the control bulk $\mathrm{CN}_{550}$ (Figure S8) were further measured. Interestingly, the $\mathrm{m} / \mathrm{z}$ fragments of $370,550,597,613$, and 614 that were assignable to the linear oligomers of the triazine unit were observed for all samples (Figure S9). Nevertheless, the relative intensity gradually decreased when the condensation temperature was elevated. Moreover, the mass spectra of $\mathrm{CN}_{\mathrm{MW} 500}$ and $\mathrm{CN}_{\text {MW580 }}$ showed 219, 420, and $621 \mathrm{~m} / \mathrm{z}$ fragments, the same as that of bulk $\mathrm{CN}_{550}$, with an interval of 201. It corresponded to the successive loss of protonated heptazine in ionization $^{35}$. A series of peaks with $\mathrm{m} / \mathrm{z}$ separated by 17, 42, 67, 151, 176, and 201 were also observed, showing the progressive ionization of heptazine to cyanamide (see more discussion in SI and Table S1). Besides, multiple LDI-TOF mass spectra measurements showed that the relative $\mathrm{m} / \mathrm{z}$ fragment intensity of 621 , assigning to heptazine trimer, successively increased during the polymerization, indicating an improved polymerization degree at a higher temperature. The by-products, including dicyandiamide, melamine, and melam during the synthesis of $\mathrm{CN}_{\mathrm{MW}} 580$, were also identified by FTIR (Figure S10a), XRD patterns (Figure S10b), and high-performance liquid chromatography (HPLC)-mass spectrometry (Figure S11).

Given the above, the detailed thermal-condensation processes of $\mathrm{CN}_{\mathrm{MWT}}$ were summarized as follows: (1) triazine repeating units with cyano-terminal groups were firstly produced from monomers; (2) they later converted into a more conjugated heptazine framework when the critical temperature (ca. $500{ }^{\circ} \mathrm{C}$ ) was reached; (3) at a higher temperature up to $580{ }^{\circ} \mathrm{C}$, the polymerization degree increased; (4) and finally, at an even higher temperature, $\mathrm{CN}_{\mathrm{MWT}}$ started to decompose (Figure S13). Notably, our results showed that the triazine unit was always accompanied by the electron-drawing cyano-terminal groups during the condensation reaction, while the heptazine unit was not. It was supposed that such molecular structures evolution would alter the HOMO- 
LUMO orbits delocalization of $\mathrm{CN}_{\mathrm{MWT}}$ and subsequently influence the ECL efficiency, which will be discussed in the following text.
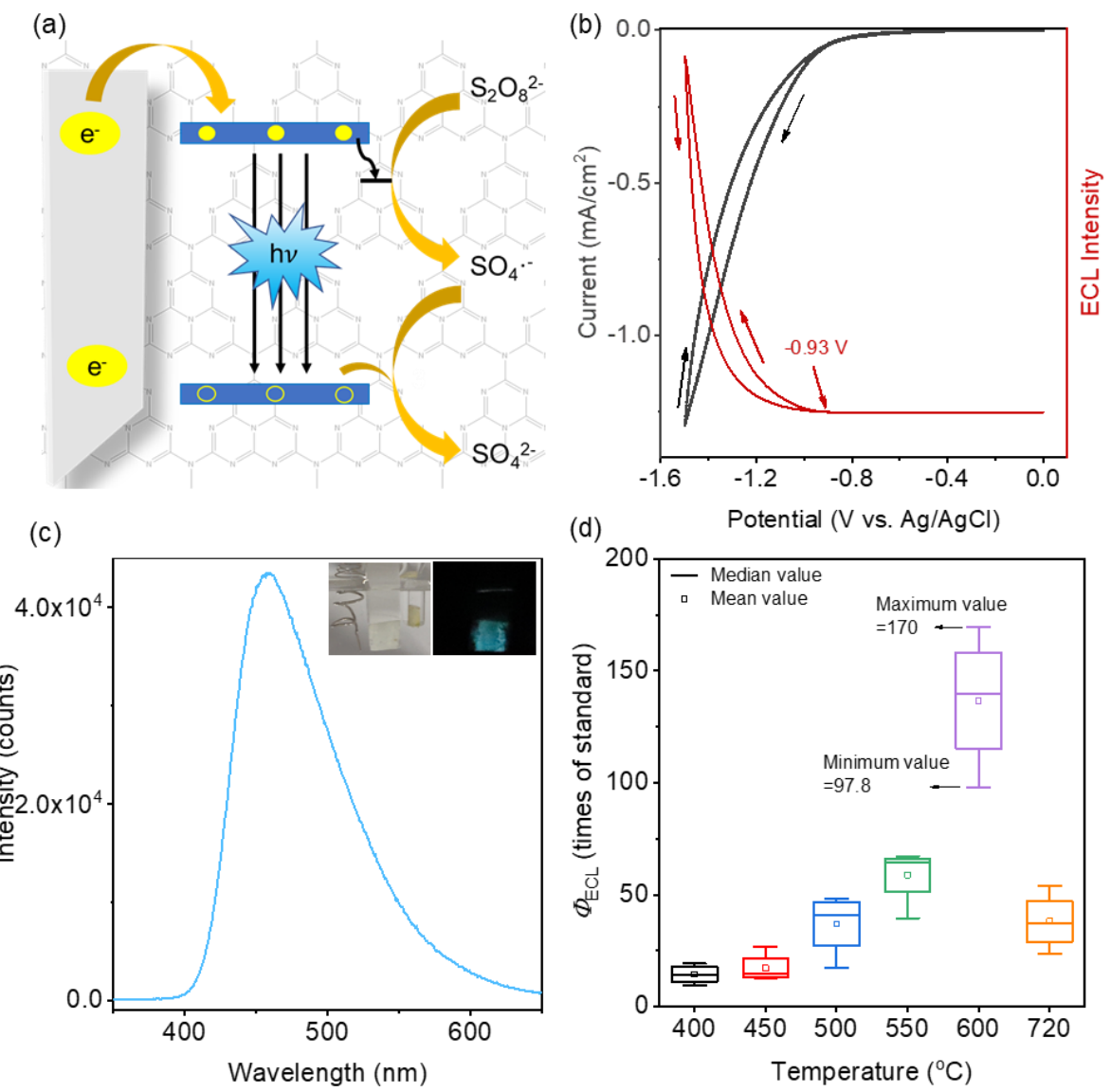

Figure 2. (a) Proposed ECL mechanism at $\mathrm{CN}_{\mathrm{MWT}}$. (b) $\mathrm{CV}$ and ECL curves of $\mathrm{CN}_{\mathrm{MW}} 580$. (c) Wavelength-resolved ECL spectrum of $\mathrm{CN}_{\mathrm{Mw}} 580$ under $-1.5 \mathrm{~V}$ vs. $\mathrm{Ag} / \mathrm{AgCl}$ that was used for calculating the total number of photons. Insets: the photographs of $\mathrm{CN}_{\mathrm{MW}} 580$ electrode before and after applying voltage in the daylight and dark. (d) The relative ECL efficiency of $\mathrm{CN}_{\text {MwT. }}$ Electrolyte: 0.01 M PBS, 0.1 M KCl and $25 \mathrm{mM} \mathrm{K}_{2} \mathrm{~S}_{2} \mathrm{O}_{8}$.

ECL is the emission of light produced by the electron transfer reaction between the electrochemically generated species in the vicinity of an electrode. ${ }^{2,36}$ Figure 2a shows that the entire ECL processes of CN can be divided into four steps. The first is the injection of electrons from the working electrode into $\mathrm{CN}^{\prime}$ 's conduction band (CB). Next, partially excited electrons reduced the co-reagent, producing potent oxidant radicals. It 
later initiated the third step, i.e., hole-generation in the valence band (VB). Lastly, the electrons in the $\mathrm{CB}$ and the holes in the VB recombine with the emission of lights. ${ }^{37}$ The cyclic voltammogram (CV) curve showed the injection of electrons (Step 1) for $\mathrm{CN}_{\mathrm{MW} 580}$ at an onset potential of ca. $-0.93 \mathrm{~V}$; simultaneously, the ECL emission was observed (Figure 2b), even by naked eyes (Figure 2c inset). The wavelength-resolved ECL spectrum in Figure 2c demonstrated an intense peak centered at ca. $460 \mathrm{~nm}$, almost identical to its optical bandgap (Figure S7), manifesting the above CB-VB transition mechanism ${ }^{30}$.

Our previous microwave-assisted synthesis work obtained a historic record cathodic ECL efficiency of ca. seven times of benchmark $\mathrm{Ru}(\mathrm{bpy}){ }_{3} \mathrm{Cl}_{2} \cdot{ }^{37}$ This study revealed that by optimizing the microwave sampling position (Figure S14), the heating temperature could be further substantially improved from prevenient $400{ }^{\circ} \mathrm{C}$ to $720{ }^{\circ} \mathrm{C}$, fully covering the condensation and decomposition temperature for $\mathrm{CN}$. Interestingly, as shown in Figure 2d, the relative ECL efficiency ( $\Phi_{\mathrm{ECL}}$, Eqn. 1) demonstrated a volcano relationship with the synthesis temperature, and the highest one of $\mathrm{CN}_{\mathrm{MW}}$ 58 reached a new milestone of 170 times of benchmark $\mathrm{Ru}(\mathrm{bpy})_{3} \mathrm{Cl}_{2}$ (see the detailed calculation in Figure S15). Thanks to the variable molecular structures discussed in the above section, $\mathrm{CN}_{\text {MWT }}$ offered a versatile platform to understand the intrinsic factors that influence $\Phi_{\mathrm{ECL}}$.

To verify how electrons participated in the ECL processes in Step 1, the electrochemical impedance spectra (EIS) and Mott-Schottky plots of different $\mathrm{CN}_{\mathrm{MWT}}$ were measured. Generally, the semicircle diameter in Nyquist plots is equivalent to the electron-transfer resistance $\left(\mathrm{R}_{\mathrm{p}}\right){ }^{38}$ and low resistance favors electrons injection from substrate electrodes to emitters for cathodic ECL (Step 1). As shown in Figure 3a and S16a, the semicircle domain decreased with condensation temperature, indicating that the higher the condensation temperature, the higher the electron conductivity. Mott-Schottky plots under dark conditions were also analyzed. Figure $\mathbf{3 b}$ showed a lower slope for $\mathrm{CN}_{\mathrm{MWT}}$ at high temperatures. As known, the slope of the Mott-Schottky plot was inversely correlated with the charge carrier density (Eqn. 2). It suggested that $\mathrm{CN}_{\mathrm{MWT}}$ at higher 
temperatures could improve the charge carrier density ${ }^{39}$ (Figure S16b), which provided the origin of the enhanced electron conductivity of $\mathrm{CN}_{\text {MWT }}$.

(a)

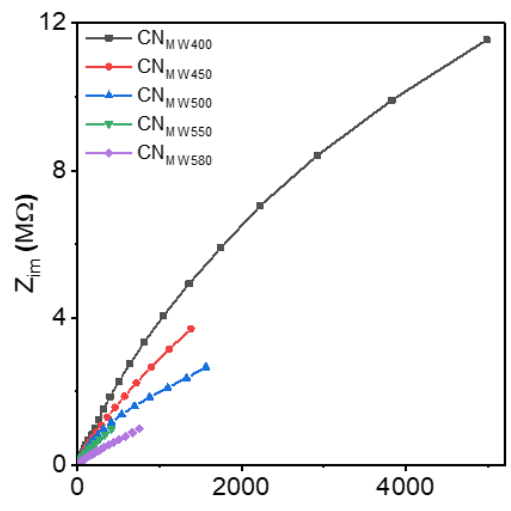

(c)

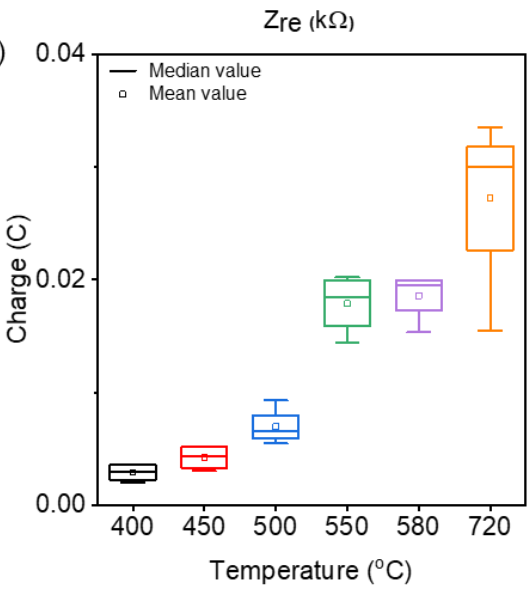

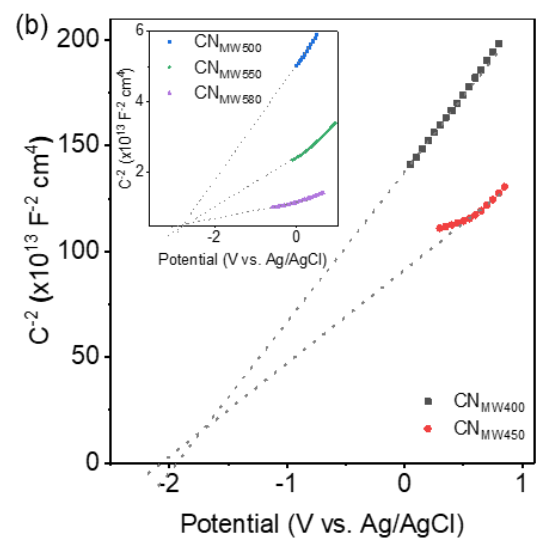

(d) $\mathrm{E}(\mathrm{V}) \mathrm{NHE}$

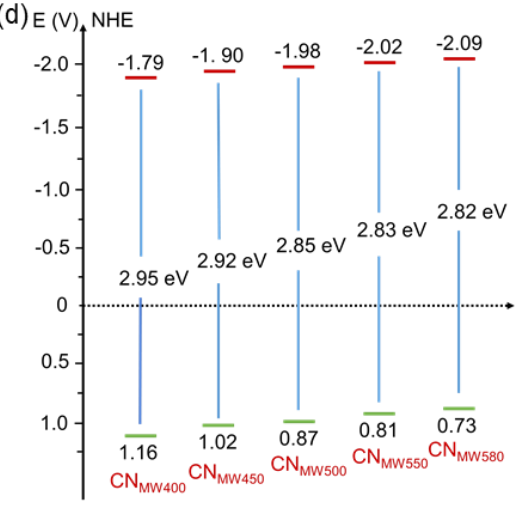

Figure 3. (a) Nyquist and (b) Mott-Schottky plots of different $\mathrm{CN}_{\mathrm{MWT}}(\mathrm{T}=400-580)$ in $0.1 \mathrm{M} \mathrm{KCl}$. The inset shows the Mott-Schottky plots of $\mathrm{CN}_{\mathrm{MWT}}(\mathrm{T}=500-580)$ under same condition. (c) Charge consumed by Faraday reactions and (d) energy level diagram of different $\mathrm{CN}_{\mathrm{MWT}}(\mathrm{T}=400-580)$.

We next explored Step 2 and 3, in which $\mathrm{K}_{2} \mathrm{~S}_{2} \mathrm{O}_{8}$ co-reagent was successively reduced, followed by the generation of holes in the VB of $\mathrm{CN}_{\mathrm{Mw}}$. The ECL intensitypotential curves in Figure S17 showed $\mathrm{CN}_{\mathrm{MWT}}$ at higher temperature demonstrated a positively shifted ECL onset potential. As enabled by the formation of more heptazine units, the increased electronic conductivity of $\mathrm{CN}_{\mathrm{MWT}}$ well supported the accelerated reduction of $\mathrm{K}_{2} \mathrm{~S}_{2} \mathrm{O}_{8}$ into $\mathrm{SO}_{4}{ }^{--}$(Step 2). The charge consumed by Faraday reactions including $\mathrm{K}_{2} \mathrm{~S}_{2} \mathrm{O}_{8}$ and $\mathrm{CN}_{\mathrm{MWT}}$ reduction could be quantitatively evaluated by 
subtracting the consumed charge during chronoamperometric measurements in electrolyte without $\mathrm{K}_{2} \mathrm{~S}_{2} \mathrm{O}_{8}$ from that with $\mathrm{K}_{2} \mathrm{~S}_{2} \mathrm{O}_{8}$. As summarized in Figure 3c, the charge consumed by $\mathrm{K}_{2} \mathrm{~S}_{2} \mathrm{O}_{8}$ reduction in the ECL processes also increased for $\mathrm{CN}_{\mathrm{MWT}}$ at high temperatures, which was supposed to generate more co-reagent radicals. To understand the formation of a hole in the $\mathrm{VB}$ of $\mathrm{CN}_{\mathrm{MWT}}$, the energy band structure of $\mathrm{CN}_{\text {MWT }}$ was further calculated by measuring the flat band potential using the onset of the photocurrent (Figure S18) and the band gap from the UV-vis absorption spectra (Figure S8). It was observed that the CB-VB position up-shifted with a shrinking gap for $\mathrm{CN}_{\mathrm{MWT}}$ at a higher temperature. As such, the strong oxidizing species, i.e., $\mathrm{SO}_{4}{ }^{--}$, would be more easily generated and further extracted an electron from VB to produce a hole (Step 3). After this step, the excited $\mathrm{CN}_{\mathrm{MWT}^{*}}$ was formed. In these regards, the electronic conductivity and $\mathrm{CB}-\mathrm{VB}$ position of $\mathrm{CN}_{\mathrm{MWT}}$ at higher temperatures were more favorable to the kinetics of Step 2 and 3 in the ECL for CNMwT.

To understand the influencing factors for the photon dynamics in ECL (Step 4), the open-circuit photovoltage (OCP) was further measured. Generally, a larger OCP upon irradiation is often associated with solid excited electron storage. It was found that the OCP of all $\mathrm{CN}_{\mathrm{MWT}}$ increased with time under the irradiation and gradually reached a plateau. Interestingly, the slopes $\left(\mathrm{k}_{1}\right)$ were higher for $\mathrm{CN}_{\mathrm{MWT}}$ at a higher temperature, indicating faster electrochemical excitation kinetics (Figure 4a), consistent with the lower ECL onset potential (Figure S18). A similar trend of the stabilized OCP under irradiation $\left(\Delta \mathrm{V}_{1}\right)$ for all $\mathrm{CN}_{\mathrm{MWT}}$ was also observed, indicating higher excited electron storage. ${ }^{40-41}$ When the light was off, the OCP rapidly subsided. The slope, an indicator of the electron-hole recombination kinetics $\left(\mathrm{k}_{2}\right)$, was also higher for $\mathrm{CN}_{\mathrm{MWT}}$ at higher temperatures. The surface deep electron-trapping state could be evaluated by the ratio of $\Delta \mathrm{V}_{2} / \Delta \mathrm{V}_{1}(\alpha) .{ }^{39,42}$ It was observed that $\alpha$ of $\mathrm{CN}_{\mathrm{MWT}}$ at higher temperature was closer to 1 , suggesting less surface deep electron-trapping state. For clarity, the value of $\Delta \mathrm{V}_{1}$, $\Delta_{2}, \mathrm{k}_{1}$, and $\mathrm{k}_{2}$ for different $\mathrm{CN}_{\mathrm{MWT}}$ are summarized in Figure S19. Thus, the OCP measurement disclosed that $\mathrm{CN}_{\mathrm{MWT}}$ at higher temperatures had higher excited electron- 
storage capacity, favorable excitation, faster electron-hole recombination kinetics, and less surface deep trapping state of electrons.

(a)

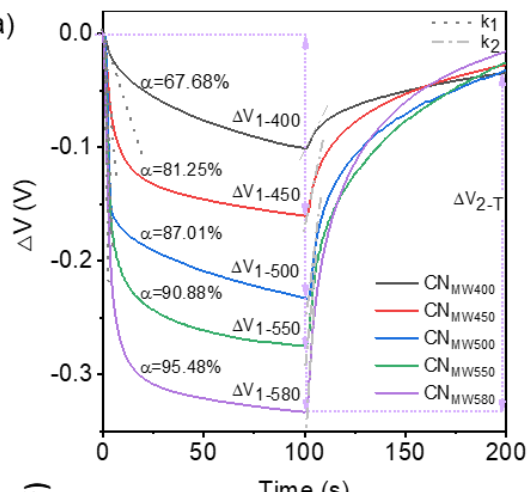

(b)

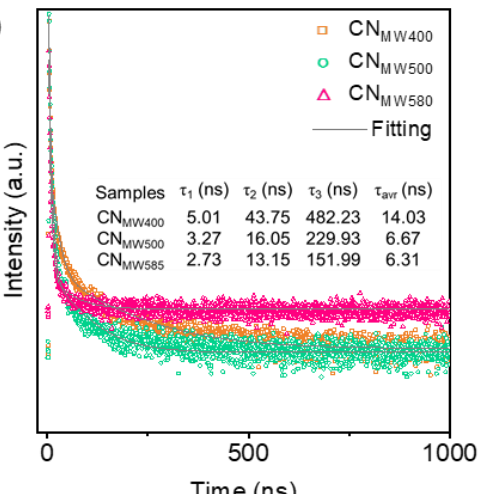

(d)

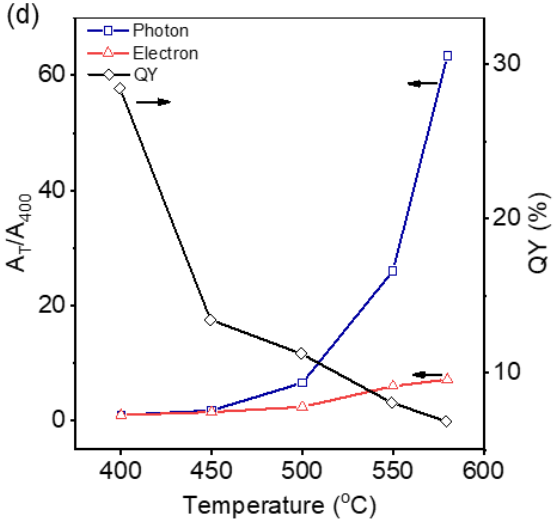

Figure 4. (a) Open circuit potential of different $\mathrm{CN}_{\mathrm{MWT}}(\mathrm{T}=400-580)$ under chopped visible light irradiation in $0.1 \mathrm{M} \mathrm{KCl}$. (b) Time-resolved PL decay spectra and (c) holes recombination efficiency of $\mathrm{CN}_{\mathrm{MWT}}(\mathrm{T}=400-580)$ evaluated by $\mathrm{PEC}$ current under chopped light biased at $-0.3 \mathrm{~V}$ vs. $\mathrm{Ag} / \mathrm{AgCl}$ in $0.1 \mathrm{M} \mathrm{KCl}$. (d) PL quantum yields, the number of emitted photons and the number of consumed electrons involved in the ECL of $\mathrm{CN}_{\mathrm{MWT}}(\mathrm{T}=400-580)$.

To confirm the above photon dynamics, the excited state of $\mathrm{CN}_{\mathrm{MWT}}$ was also studied using the time-resolved PL decay spectra (Figure 4b), thanks to the similar CB-VB transition in ECL and PL. Three different processes contribute to the lifetime: the nonradiative process $\left(\tau_{1}\right)$, radiative process $\left(\tau_{2}\right)$, and energy transfer process $\left(\tau_{3}\right){ }^{43-44}$ Among them, $\tau_{2}$ is directly related to the recombination of photogenerated electron- 
hole pairs, ${ }^{43,45}$ which was calculated to be $43.75,16.05$, and $13.15 \mathrm{~ns}$ for $\mathrm{CN}_{\mathrm{MWT}}$ ( $\mathrm{T}=400,500$ and 580), respectively. In general, a shorter PL decay lifetime of the radiative process often indicates a faster recombination rate for electron-hole pairs, ${ }^{46}$ while an elongated one would result from the accumulation of excited electrons in the deep trapping state. To support this hypothesis for $\mathrm{CN}_{\mathrm{MWT}}$, triethanolamine (TEOA), an efficient hole scavenger, was added to the electrolytes. Assuming that most holes are successfully extracted in the system, the normalized photocurrent after the addition of TEOA could be set as $100 \%{ }^{47-48}$ Based on this speculation, the calculated electron-hole recombination efficiency ( $\eta_{r e}$, Eqn. 4) of $\mathrm{CN}_{\mathrm{MWT}}$ at higher temperature was higher (Figure 4c, S20), supporting the as-observed shorter PL decay lifetime and consistent with the OCP results (Figure 4a). Similarly, the $\mathrm{R}_{\mathrm{p}}$ by EIS plots (Figure S21a and b) and the charge carrier density by Mott-Schottky plots (Figure S21b and c) under irradiation for $\mathrm{CN}_{\mathrm{MWT}}$ also showed the consistent dependence on the condensation temperature. For instance, the charge carrier density of $\mathrm{CN}_{\mathrm{MW} 580}$ was quantitatively nearly 120 times that of $\mathrm{CN}_{\mathrm{MW} 400}$ under irradiation, showing the critical role of condensation temperature in enhancing the photon dynamics process.

The above results revealed that higher condensation temperature favored both the electron transfer and radiative process. Nonetheless, the detailed dependences were different. As shown in Figure 4d, the turnaround temperature for consumed electrons and emitted photons was observed both at ca. $500{ }^{\circ} \mathrm{C}$, but beyond which, the former gradually reached a plateau, while the latter sharply boosted up to $580{ }^{\circ} \mathrm{C}$. It should be noted that 500 and $580^{\circ} \mathrm{C}$ were the critical temperatures for transforming triazine into heptazine and the decomposition of $\mathrm{CN}$, respectively. According to the definition of $\Phi_{\mathrm{ECL}}$, it suggested that in the stable scope of carbon nitrides, the higher ratio of heptazine units, the higher $\Phi_{\mathrm{ECL}}$. In contrast, the PL quantum yields (QY) of the $\mathrm{CN}_{\mathrm{MWT}}$ demonstrated a different dependence on the core repeating units (Figure 4d), indicating a distinctive mechanism. 
(a)

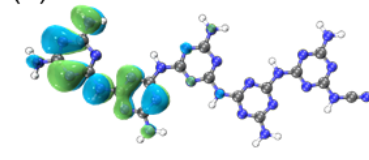

LUMO-ODI: 14.32

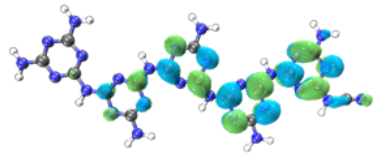

HOMO-ODI: 7.75 (b)

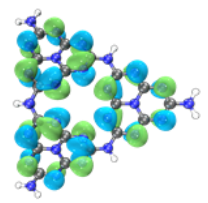

LUMO-ODI: 5.29

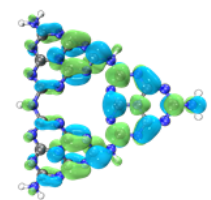

HOMO-ODI: 5.78 (c)

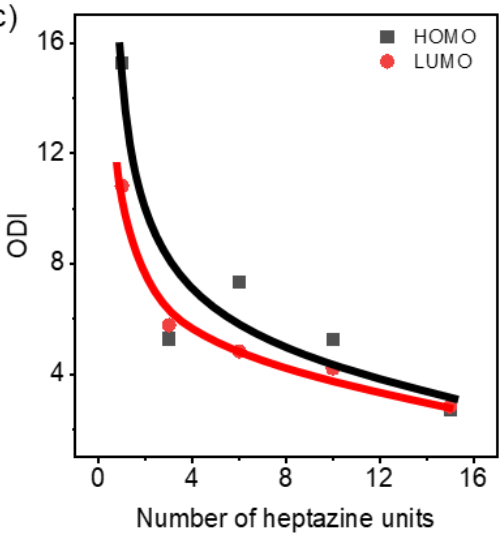

(d)

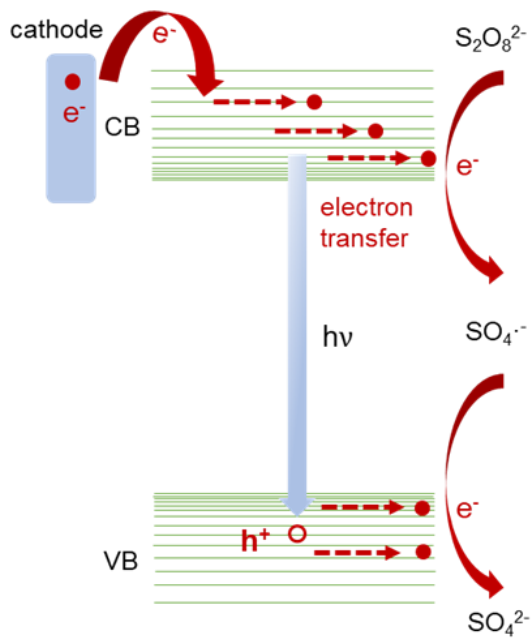

(e)
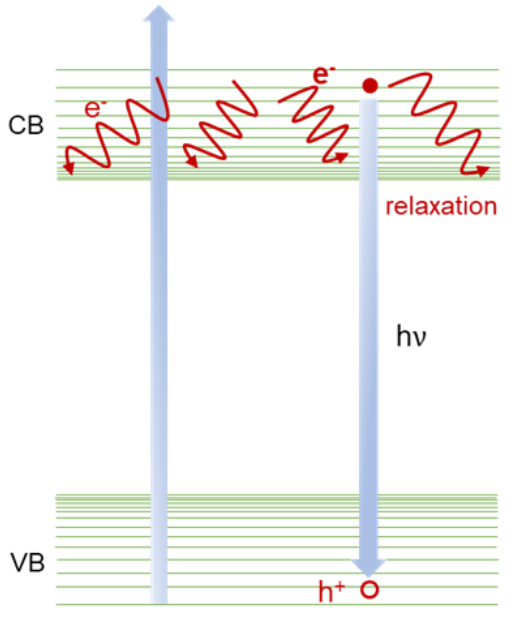

Figure 5. Isosurfaces of the LUMO (top) and HOMO (bottom) of the representative molecular structures of (a) $\mathrm{CN}_{\mathrm{MW} 400}$ and (b) $\mathrm{CN}_{\mathrm{MW} 580}$ along with the orbital delocalization index. (c) Plot of ODI for HOMO-LUMO with the different number of heptazine rings. Scheme of the proposed charge transfer in (d) ECL and (e) PL of $\mathrm{CN}_{\text {MWT. }}$

In general, the ECL kinetics, such as electronic conductivity, excited electron-storage capacity, surface deep electron-trapping state, charge carrier density, and electron-hole recombination efficiency, were are all associated with the electronic structure of luminophores, for which, the orbital delocalization is supposed to be a practical desciptor. ${ }^{49-51}$ To get more insights into the improved $\Phi_{\mathrm{ECL}}$ for $\mathrm{CN}_{\mathrm{MWT}}$, the orbital delocalization index (ODI) of HOMO-LUMO for the typical fragments during the 
successive thermal condensation of $\mathrm{CN}$ were quantitatively calculated by using DFT methods. ${ }^{52}$ The $O D I_{i}$ is defined as $0.01 \times \sum_{A} \Theta_{A, i}{ }^{2}$, where $\Theta_{A, i}$ is the contribution degree of $A$ atom for the $i$ obit. The lower ODI in value, the higher the orbital delocalization. In addition, the ODI range is $(0,100]$. It was found that due to the lone pair electrons, cyano-terminal groups, which always accompanied the generation of trazine during the condensation below the critical temperature of $400{ }^{\circ} \mathrm{C}$, mostly predominated the contribution for the HOMO and LUMO of $\mathrm{CN}_{\mathrm{MWT}}$ (Figure 5a), manifesting a higher ODI. In contrast, the ODI of HOMO and LUMO for CNMwT with heptazine framework decreased (Figure 5b) and became even lower with a higher polymerization degree (Figure 5c), indicating electrons were ready to transfer in a more polymerized structure. Such significant ODI changes for different CN fragments supported the experimental observation that $\mathrm{CN}_{\mathrm{MWT}}$ at higher temperatures had favorable electron injection in dark and photon emission afterward. Therefore, during the thermal condensation of $\mathrm{CN}$, the structure transformation regarding the terminal groups and triazine/heptazine core frameworks was essentially associated with a gradual improvement in the orbital delocalization. Factoring out the complicated structure evolution, ODI could be regarded as a unified intrinsic factor for $\Phi_{\mathrm{ECL}}$ of CN, i.e., the lower ODI, the higher $\Phi_{\mathrm{ECL}}$.

For clarity, the possible charge-transfer pathway for ECL (Figure 5c) and PL (Figure 5d) of $\mathrm{CN}_{\mathrm{MWT}}$ was briefly proposed. Due to the unique electrochemical excitation, an efficient obits delocalization would promote electron injection and co-reagent reduction reaction kinetics. In contrast, the same situation was often associated with non-radiative decay pathways for photoexcitation, leading to a PL quenching. Understanding the effects of electron delocalization on the unique electrochemical excitation and light emission for ECL would unlock the intrinsic factors for boosting $\Phi_{E C L}$. As a result, owing to the enhanced HOMO and LUMO delocalization, the as-synthesized $\mathrm{CN}_{\mathrm{MW}} 580$ demonstrated the highest $\Phi_{\mathrm{ECL}}$ in this work, reaching a new milestone of 134-fold greater than the benchmark $\mathrm{Ru}(\mathrm{bpy})_{3} \mathrm{Cl}_{2}$ (Figure 2d). Moreover, taking detection of $\mathrm{NaNO}_{2}$ as an example application, a near tenfold larger slope of the calibration curve 
was obtained by using $\mathrm{CN}_{\mathrm{Mw}}$ 580, compared to $\mathrm{CN}_{\mathrm{MW} 400}$ (Figure S22). It evidently suggested that $\mathrm{CN}_{\mathrm{MWT}}$ with higher $\Phi_{\mathrm{ECL}}$ held great potentials in developing chemical sensors with superior sensitivity.

\section{Conclusion}

In summary, we report that the orbital delocalization of $\mathrm{CN}$ was a practically unifying factor for its ECL efficiency. The comprehensive characterizations, including LDI-TOF mass spectroscopy, confirmed the critical molecular transformation from triazine to heptazine basal frameworks at $500{ }^{\circ} \mathrm{C}$, accompanying the disappearance of cyanoterminal groups. Apart from PL property in previous studies, each electron- and photonparticipated process in ECL of CN was further systematically explored to examine the ECL kinetics, such as electronic conductivity, excited electron-storage capacity, surface deep electron-trapping state, charge carrier density, and electron-hole recombination efficiency. The resulting DFT calculation disclosed the intrinsic correlation between molecular structure and ECL kinetics, i.e., behind the complicated molecular structure evolution, the orbital delocalization of $\mathrm{CN}$ was essentially improved at successive elevated condensation temperature, which favored the electron injection in excitation and photon emission afterward in ECL. As a result, interestingly, the cathodic $\Phi_{\mathrm{ECL}}$ of $\mathrm{CN}$ calcining at $580{ }^{\circ} \mathrm{C}$ before the decomposition was remarkably improved to a new milestone up to ca. 170 -fold greater than that of benchmark $\mathrm{Ru}(\mathrm{bpy})_{3} \mathrm{Cl}_{2}$. This work demonstrates that a better understanding of intrinsic factors, such as the orbital delocalization for $\mathrm{CN}$, is promising to unlock luminophores with higher $\Phi_{\mathrm{ECL}}$ and pave more demanding applications.

\section{Experimental Procedures}

Reagent. Cyanamide (CA, 99\%) was purchased from Energy Chemical, China. Potassium peroxodisulfate $\left(\mathrm{K}_{2} \mathrm{~S}_{2} \mathrm{O}_{8}\right)$, potassium chloride $(\mathrm{KCl})$, sodium dihydrogen phosphate dihydrate $\left(\mathrm{NaH}_{2} \mathrm{PO}_{4} \cdot 2 \mathrm{H}_{2} \mathrm{O}\right)$, disodium hydrogen phosphate dodecahydrate $\left(\mathrm{Na}_{2} \mathrm{HPO}_{4} \cdot 12 \mathrm{H}_{2} \mathrm{O}\right)$, triethanolamine (TEOA) and sodium nitrite $\left(\mathrm{NaNO}_{2}\right)$ were obtained 
from Shanghai Macklin Biochemical Co. Ltd., China. Fluorine-doped tin oxide (FTO) glasses (12-14 $\Omega /$ sq, Zhuhai Kaivo Optoelectronic Technology Co., Ltd., China) was ultrasonically washed with acetone, alcohol, and ultrapure water for $15 \mathrm{~min}$, respectively, and then dried with high pure nitrogen gas flow before use. Ultrapure water $(18.2 \mathrm{M} \Omega \cdot \mathrm{cm})$ was obtained from a Direct-Q 3 UV pure water purification system (Millipore, USA) throughout all experiments. Unless otherwise specified, all the other reagents were of analytical grade and applied without further purification.

Characterization. Fourier transformed infrared spectra (FT-IR) were recorded using Nicolet iS10 FT-IR spectrometer, equipped with an attenuated total reflection (ATR) setup (Thermo, USA). The structure of $\mathrm{CN}_{\mathrm{MwT}}$ was obtained by matrix-free laser desorption/ionization time-of-flight mass (LDI-TOF-MS, AB Sciex 5800, America). The morphology of the $\mathrm{CN}_{\mathrm{MWT}}$ electrode were investigated by FEI Inspect F50 scanning electron microscope (FEI, USA). The XRD patterns were measured by using Ultima IV (Rigaku, Japan). X-ray photoelectron spectroscopy (XPS) was taken on an ESCALAB 250XI electron spectrometer (Thermo, USA) with monochromatic Al Ka $\mathrm{X}$-rays $(\mathrm{h} v=1486.6 \mathrm{eV})$ as the excitation source, and the binding energy were corrected by reference $\mathrm{C} 1 \mathrm{~s}$ level to $284.6 \mathrm{eV}$ to compensate for the specimen charging. The UVvis absorption spectra were measured on a Cary 100 (Agilent, Singapore) with a diffusereflectance accessory, and $\mathrm{BaSO}_{4}$ was used as a standard reference (100\% reflectance). The photoluminescence (PL) spectra were performed on a Fluoromax-4 (Horiba Jobin Yvon, Japan). The time-resolved PL spectra were performed with fluorescence spectrometer (PluoroLog 3-TCSPC, Horiba Jobin Yvon, Japan). The high-performance liquid chromatography (HPLC, Agilent, 1260-Infifinity) at a detection wavelength of $230 \mathrm{~nm}$ with a methanol/water mixture $(80: 20, \mathrm{v} / \mathrm{v})$ as the mobile phase. Thermal gravimetric analysis (TGA) was performed using a (TG209 F3, Netzsch, Germany) analyzer with a heating rate of $10{ }^{\circ} \mathrm{C} / \mathrm{min}$ from $25{ }^{\circ} \mathrm{C}$ to $800{ }^{\circ} \mathrm{C}$ under a nitrogen atmosphere.

Preparation of $C N$ photoelectrode. Firstly, CA was heated at $80{ }^{\circ} \mathrm{C}$ and melted. Then, $30 \mu \mathrm{L}$ of CA was dropped on the conductive side of FTO. After that, the microwave 
oven (M1-L213B, $2.45 \mathrm{GHz}$, Midea, China) were used to heat CA using FTO as microwave interaction agent operating with the power of $700 \mathrm{~W}$ and cooled to room temperature naturally. The thermal imaging device (AnalyzIR FOTRIC 280, China) were used for monitoring the $\mathrm{CN}_{\mathrm{MW}}$ synthesis process. A microwave leakage detector (DT-2G, CEM, China) was used to monitor external field intensities around the oven in order to safety precaution.

ECL Measurements. The ECL intensity measurements were conducted on an ECL analyzer system (MPI-E, Xi' an Ruimai Analytical Instruments Co. Ltd., China). The voltage of photomultiplier tube (PMT) for collecting the ECL signal was biased at 400 $\mathrm{V}$ during detection. The supporting electrolyte was $0.1 \mathrm{M} \mathrm{KCl}$ with $25 \mathrm{mM} \mathrm{K}_{2} \mathrm{~S}_{2} \mathrm{O}_{8}$ in $0.01 \mathrm{M}$ PBS (pH 7.4). ${ }^{31,53}$ The ECL emission spectra were recorded by integrating CHI 400C with an Fluoromax-4 FL spectrophotometer, where the slit width was $20 \mathrm{~nm}$.

Relative ECL efficiency $\left(\Phi_{\mathrm{ECL}}\right) . \Phi_{\mathrm{ECL}}$ are defined as the ratio of the number of photons produced per electron transferred between the oxidized and reduced analyte species relative to that of $\mathrm{Ru}(\text { bpy })_{3} \mathrm{Cl}_{2} / \mathrm{K}_{2} \mathrm{~S}_{2} \mathrm{O}_{8}$, using Eqn. 1: ${ }^{53-54}$

$\phi_{E C L}=\frac{\left(\frac{\int E C L d t}{\int \text { Current dt }}\right) x}{\left(\frac{\int E C L d t}{\int \text { Current dt }}\right) s t} \times 100 \%$

where "ECL" and "Current" represent integrated ECL intensity from the accumulated ECL spectrum and electrochemical current values respectively, "st" refers to the $\mathrm{Ru}(\mathrm{bpy})_{3} \mathrm{Cl}_{2} / \mathrm{K}_{2} \mathrm{~S}_{2} \mathrm{O}_{8}$ standard and " $x$ " refers to the analyte. The potential was fixed at $1.5 \mathrm{~V}$ vs. $\mathrm{Ag} / \mathrm{AgCl}$ by chronoamperometry in $0.01 \mathrm{M}$ PBS (pH 7.4) containing $25 \mathrm{mM}$ $\mathrm{K}_{2} \mathrm{~S}_{2} \mathrm{O}_{8}$ and $0.1 \mathrm{M} \mathrm{KCl}$.

Photoelectrochemical measurements. All the electrochemical measurements were performed with a conventional three-electrode system, consisting of $\mathrm{CN}_{\mathrm{MWT}}$ on FTO electrode, platinum wires, $\mathrm{Ag} / \mathrm{AgCl}$ in saturated $\mathrm{KCl}$ as working electrode, counter electrode, and reference electrode, respectively. The PEC experiments were measured out in $0.1 \mathrm{M} \mathrm{KCl}$ at ambient condition. The light source to simulate the sunlight was obtained from a $150 \mathrm{~W}$ Xe lamp and the average light intensity was $100 \mathrm{~mW} / \mathrm{cm}^{2}$. The 
electrochemical impedance spectroscopy (EIS), open circus potential (OCP) and MottSchottky plots were recorded in a Reference 600 potentiostat/galvanostat/ZRA (Gamry, USA). The potentials were measured against the $\mathrm{Ag} / \mathrm{AgCl}$ (saturated $\mathrm{KCl}$ ). The working electrode was irradiated from the backside in order to minimize the influence of thickness of the semiconductor layer. The Mott-Schottky equation (Eqn. 2) simply relates $C$ to the applied potential $V$ relative to its $V_{f b}$ and other parameters of the semiconductor as follows: ${ }^{39,55}$

$\frac{1}{C^{2}}=\frac{2}{\varepsilon \varepsilon_{0 A^{2} e N_{D}}}\left(V-V_{f b}-\frac{k_{B} T}{e}\right)$

Slope $=\frac{2}{\varepsilon \varepsilon_{0 A^{2} e N_{D}}}$

where $\varepsilon$ and $\varepsilon_{0}$ are the dielectric constant and the vacuum permittivity, respectively, $A$ is the area, $e$ is the electronic charge, $V_{f b}$ is the flat-band potential, $N_{D}$ and the donor concentration, (for an n-type semiconductor photoanode), or acceptor concentration, $\mathrm{V}$ is applied potential, $k_{B}$ is the Boltzmann constant, and $T$ is the temperature. The $N_{D}$ is proportional to the inverse of the slope.

Hole recombination efficiency. The hole recombination efficiency was calculated using Eqn. $4:^{47,56}$

$\eta_{r e}(\%)=1-\frac{J_{K C l}}{J_{T E O A}} \times 100 \%$

It is assumed that the recombination efficiency of photogenerated carriers in the system is $100 \%$ after the addition of a hole scavenger $\left(10 \% \mathrm{v} / \mathrm{v}\right.$ TEOA). $J_{K C l}$ is the photocurrent density obtained in $0.1 \mathrm{M} \mathrm{KCl}$ aqueous solution, while $J_{T E O A}$ is the photocurrent density obtained in $0.1 \mathrm{M} \mathrm{KCl}$ containing $10 \%(\mathrm{v} / \mathrm{v})$ TEOA.

Computational methods. Density functional theory (DFT) calculations were performed with Gaussian 16 (revision A03). ${ }^{57}$ The models were optimized at the M06-2X/6$311 \mathrm{~g}(\mathrm{~d}, \mathrm{p})$ level without imaginary frequency. The ODI was calculated by Multiwfn (revision 3.8). ${ }^{58}$ The images of isosurfaces of the LUMO and HOMO were obtained from Visual Molecular Dynamics (VMD, revision 1.9.3) and Multiwfn (revision 3.8). 


\section{Reference}

1. Pan, D.; Fang, Z.; Yang, E.; Ning, Z.; Zhou, Q.; Chen, K.; Zheng, Y.; Zhang, Y.; Shen, Y., Facile Preparation of $\mathrm{WO}_{3-\mathrm{x}}$ Dots with Remarkably Low Toxicity and Uncompromised Activity as Co-reactants for Clinical Diagnosis by Electrochemiluminescence. Angew. Chem. Int. Ed. 2020, 59, 16747-16754.

2. Voci, S.; Goudeau, B.; Valenti, G.; Lesch, A.; Jović, M.; Rapino, S.; Paolucci, F.; Arbault, S.; Sojic, N., Surface-Confined Electrochemiluminescence Microscopy of Cell Membranes. J. Am. Chem. Soc. 2018, 140, 14753-14760.

3. Zhang, J.; Jin, R.; Jiang, D.; Chen, H.-Y., Electrochemiluminescence-Based Capacitance Microscopy for Label-Free Imaging of Antigens on the Cellular Plasma Membrane. J. Am. Chem. Soc. 2019, 141, 10294-10299.

4. Yang, Y.; Yao, L.-Y.; Liang, W.-B.; Huang, W.; Zhang, Y.-J.; Zhang, J.-L.; Yuan, R.; Xiao, D.-R., Highly efficient electrochemiluminescence resonance energy transfer material constructed from an AIEgen-based 2D ultrathin metal-organic layer for thrombin detection. Chem. Commun. 2021, 57, 4323-4326.

5. Zhou, X.; Zhu, D.; Liao, Y.; Liu, W.; Liu, H.; Ma, Z.; Xing, D., Synthesis, labeling and bioanalytical applications of a tris(2,2'-bipyridyl)ruthenium(II)-based electrochemiluminescence probe. Nat. Protoc. 2014, 9, 1146-1159.

6. Zanut, A.; Fiorani, A.; Canola, S.; Saito, T.; Ziebart, N.; Rapino, S.; Rebeccani, S.; Barbon, A.; Irie, T.; Josel, H.-P.; Negri, F.; Marcaccio, M.; Windfuhr, M.; Imai, K.; Valenti, G.; Paolucci, F., Insights into the mechanism of coreactant electrochemiluminescence facilitating enhanced bioanalytical performance. Nat. Commun. 2020, 11, 1-9.

7. Chen, A.; Liang, W.; Wang, H.; Zhuo, Y.; Chai, Y.; Yuan, R., Anodic Electrochemiluminescence of Carbon Dots Promoted by Nitrogen Doping and Application to Rapid Cancer Cell Detection. Anal. Chem. 2019, 92, 1379-1385.

8. Rubinstein, I.; Bard, A. J., Electrogenerated chemiluminescence. 37. Aqueous ecl systems based on tris(2,2'-bipyridine)ruthenium ${ }_{3}{ }^{2+}$ and oxalate or organic acids. J. Am. Chem. Soc. 2002, 103, 512-516.

9. Ishimatsu, R.; Matsunami, S.; Kasahara, T.; Mizuno, J.; Edura, T.; Adachi, C.; Nakano, K.; Imato, T., Electrogenerated Chemiluminescence of Donor-Acceptor Molecules with Thermally Activated Delayed Fluorescence. Angew. Chem. Int. Ed. 2014, 126, 7113-7116.

10. Zhang, R.; Tong, F.; Yang, L.; Adsetts, J. R.; Yan, T.; Wang, R.; Ding, Z.; Wang, H.-B., Facile synthesis and efficient electrochemiluminescence of a readily accessible pyridopyrimidine. Chem. Commun. 2018, 54, 9897-9900.

11. Cao, Z.; Shu, Y.; Qin, H.; Su, B.; Peng, X., Quantum Dots with Highly Efficient, Stable, and Multicolor Electrochemiluminescence. ACS Cent. Sci. 2020, 6, 1129-1137. 12. Chen, S.; Ma, H.; Padelford, J. W.; Qinchen, W.; Yu, W.; Wang, S.; Zhu, M.; Wang, G., Near Infrared Electrochemiluminescence of Rod-Shape 25-Atom AuAg Nanoclusters That Is Hundreds-Fold Stronger Than That of Ru(bpy) 3 Standard. J. Am. Chem. Soc. 2019, 141, 9603-9609.

13. Carrara, S.; Aliprandi, A.; Hogan, C. F.; De Cola, L., Aggregation-Induced 
Electrochemiluminescence of Platinum(II) Complexes. J. Am. Chem. Soc. 2017, 139, 14605-14610.

14. Han, Z.; Zhang, Y.; Wu, Y.; Li, Z.; Bai, L.; Huo, S.; Lu, X., Substituent-Induced Aggregated State Electrochemiluminescence of Tetraphenylethene Derivatives. Anal. Chem. 2019, 91, 8676-8682.

15. Wang, N.; Gao, H.; Li, Y.; Li, G.; Chen, W.; Jin, Z.; Lei, J.; Wei, Q.; Ju, H., Dual Intramolecular Electron Transfer for In Situ Coreactant-Embedded Electrochemiluminescence Microimaging of Membrane Protein. Angew. Chem. Int. Ed. 2020, 60, 197-201.

16. Swanick, K. N.; Ladouceur, S.; Zysman-Colman, E.; Ding, Z., Self-Enhanced Electrochemiluminescence of an Iridium(III) Complex: Mechanistic Insight. Angew. Chem. Int. Ed. 2012, 124, 11241-11244.

17. Booker, C.; Wang, X.; Haroun, S.; Zhou, J.; Jennings, M.; Pagenkopf, B. L.; Ding, Z., Tuning of Electrogenerated Silole Chemiluminescence. Angew. Chem. Int. Ed. 2008, 47, 7731-7735.

18. Oh, J.-W.; Lee, Y. O.; Kim, T. H.; Ko, K. C.; Lee, J. Y.; Kim, H.; Kim, J. S., Enhancement of Electrogenerated Chemiluminescence and Radical Stability by Peripheral Multidonors on Alkynylpyrene Derivatives. Angew. Chem. Int. Ed. 2009, 48, 2522-2524.

19. Jiang, D.; Du, X.; Liu, Q.; Hao, N.; Qian, J.; Dai, L.; Mao, H.; Wang, K., Anchoring $\mathrm{AgBr}$ nanoparticles on nitrogen-doped graphene for enhancement of electrochemiluminescence and radical stability. Chem. Commun. 2015, 51, 4451-4454. 20. Hesari, M.; Lu, J.-s.; Wang, S.; Ding, Z., Efficient electrochemiluminescence of a boron-dipyrromethene (BODIPY) dye. Chem. Commun. 2015, 51, 1081-1084.

21. Wei, X.; Zhu, M. J.; Cheng, Z.; Lee, M.; Yan, H.; Lu, C.; Xu, J. J., AggregationInduced Electrochemiluminescence of Carboranyl Carbazoles in Aqueous Media. Angew. Chem. Int. Ed. 2019, 58, 3162-3166.

22. Peng, H.; Huang, Z.; Deng, H.; Wu, W.; Huang, K.; Li, Z.; Chen, W.; Liu, J., Dual Enhancement of Gold Nanocluster Electrochemiluminescence: Electrocatalytic Excitation and Aggregation-Induced Emission. Angew. Chem. Int. Ed. 2019, 59, 99829985.

23. Adsetts, J. R.; Hoesterey, S.; Gao, C.; Love, D. A.; Ding, Z., Electrochemiluminescence and Photoluminescence of Carbon Quantum Dots Controlled by Aggregation-Induced Emission, Aggregation-Caused Quenching, and Interfacial Reactions. Langmuir 2020, 36, 14432-14442.

24. Han, Z.; Yang, Z.; Sun, H.; Xu, Y.; Ma, X.; Shan, D.; Chen, J.; Huo, S.; Zhang, Z.; Du, P.; Lu, X., Electrochemiluminescence Platforms Based on Small Water-Insoluble Organic Molecules for Ultrasensitive Aqueous-Phase Detection. Angew. Chem. Int. Ed. 2019, 58, 5915-5919.

25. Liu, X.; Shi, L.; Niu, W.; Li, H.; Xu, G., Environmentally Friendly and Highly Sensitive Ruthenium(II) Tris(2,2'-bipyridyl) Electrochemiluminescent System Using 2(Dibutylamino)ethanol as Co-Reactant. Angew. Chem. Int. Ed. 2007, 46, 421-424.

26. Lv, Y.; Chen, S.; Shen, Y.; Ji, J.; Zhou, Q.; Liu, S.; Zhang, Y., Competitive MultipleMechanism-Driven Electrochemiluminescent Detection of 8-Hydroxy-2'- 
deoxyguanosine. J. Am. Chem. Soc. 2018, 140, 2801-2804.

27. Ji, J.; Wen, J.; Shen, Y.; Lv, Y.; Chen, Y.; Liu, S.; Ma, H.; Zhang, Y., Simultaneous Noncovalent Modification and Exfoliation of 2D Carbon Nitride for Enhanced Electrochemiluminescent Biosensing. J. Am. Chem. Soc. 2017, 139, 11698-11701.

28. Feng, Q.-M.; Shen, Y.-Z.; Li, M.-X.; Zhang, Z.-L.; Zhao, W.; Xu, J.-J.; Chen, H.Y., Dual-Wavelength Electrochemiluminescence Ratiometry Based on Resonance Energy Transfer between Au Nanoparticles Functionalized g- $\mathrm{C}_{3} \mathrm{~N}_{4}$ Nanosheet and $\mathrm{Ru}(\mathrm{bpy}) 3^{2+}$ for microRNA Detection. Anal. Chem. 2015, 88, 937-944.

29. Zou, R.; Lin, Y.; Lu, C., Nitrogen Vacancy Engineering in Graphitic Carbon Nitride for Strong, Stable, and Wavelength Tunable Electrochemiluminescence Emissions. Anal. Chem. 2021, 93, 2678-2686.

30. Zhao, T.; Zhou, Q.; Lv, Y.; Han, D.; Wu, K.; Zhao, L.; Shen, Y.; Liu, S.; Zhang, Y., Ultrafast Condensation of Carbon Nitride on Electrodes with Exceptional Boosted Photocurrent and Electrochemiluminescence. Angew. Chem. Int. Ed. 2019, 59, 11391143.

31. Zhou, Z.; Shang, Q.; Shen, Y.; Zhang, L.; Zhang, Y.; Lv, Y.; Li, Y.; Liu, S.; Zhang, Y., Chemically Modulated Carbon Nitride Nanosheets for Highly Selective Electrochemiluminescent Detection of Multiple Metal-ions. Anal. Chem. 2016, 88, 6004-6010.

32. Zhou, Z.; Wang, J.; Yu, J.; Shen, Y.; Li, Y.; Liu, A.; Liu, S.; Zhang, Y., Dissolution and Liquid Crystals Phase of 2D Polymeric Carbon Nitride. J. Am. Chem. Soc. 2015, 137, 2179-2182.

33. Huang, C.; Wen, Y.; Ma, J.; Dong, D.; Shen, Y.; Liu, S.; Ma, H.; Zhang, Y., Unraveling fundamental active units in carbon nitride for photocatalytic oxidation reactions. Nat. Commun. 2021, 12, 320.

34. Wang, W.; Zhang, H.; Zhang, S.; Liu, Y.; Wang, G.; Sun, C.; Zhao, H., PotassiumIon-Assisted Regeneration of Active Cyano Groups in Carbon Nitride Nanoribbons: Visible-Light-Driven Photocatalytic Nitrogen Reduction. Angew. Chem. Int. Ed. 2019, 58, 16644-16650.

35. Lau, V. W.-h.; Mesch, M. B.; Duppel, V.; Blum, V.; Senker, J.; Lotsch, B. V., LowMolecular-Weight Carbon Nitrides for Solar Hydrogen Evolution. J. Am. Chem. Soc. 2015, 137, 1064-1072.

36. Valenti, G.; Scarabino, S.; Goudeau, B.; Lesch, A.; Jović, M.; Villani, E.; Sentic, M.; Rapino, S.; Arbault, S.; Paolucci, F.; Sojic, N., Single Cell Electrochemiluminescence Imaging: From the Proof-of-Concept to Disposable DeviceBased Analysis. J. Am. Chem. Soc. 2017, 139, 16830-16837.

37. Zhao, T.; Zhou, Q.; Lv, Y.; Han, D.; Wu, K.; Zhao, L.; Shen, Y.; Liu, S.; Zhang, Y., Ultrafast Condensation of Carbon Nitride on Electrodes with Exceptional Boosted Photocurrent and Electrochemiluminescence. Angew. Chem. Int. Ed. 2019, 1139-1143. 38. Jiang, W.; Zhao, Y.; Zong, X.; Nie, H.; Niu, L.; An, L.; Qu, D.; Wang, X.; Kang, Z.; Sun, Z., Photocatalyst for High-Performance $\mathrm{H}_{2}$ Production: Ga-Doped Polymeric Carbon Nitride. Angew. Chem. Int. Ed. 2021, 60, 6124-6129.

39. Ruan, Q.; Miao, T.; Wang, H.; Tang, J., Insight on Shallow Trap States-Introduced Photocathodic Performance in n-Type Polymer Photocatalysts. J. Am. Chem. Soc. 2020, 
142, 2795-2802.

40. Lau, V. W.-h.; Klose, D.; Kasap, H.; Podjaski, F.; Pignié, M.-C.; Reisner, E.; Jeschke, G.; Lotsch, B. V., Dark Photocatalysis: Storage of Solar Energy in Carbon Nitride for Time-Delayed Hydrogen Generation. Angew. Chem. Int. Ed. 2017, 56, 510 514.

41. Che, W.; Cheng, W.; Yao, T.; Tang, F.; Liu, W.; Su, H.; Huang, Y.; Liu, Q.; Liu, J.; $\mathrm{Hu}$, F.; Pan, Z.; Sun, Z.; Wei, S., Fast Photoelectron Transfer in (Cring) $-\mathrm{C}_{3} \mathrm{~N}_{4}$ Plane Heterostructural Nanosheets for Overall Water Splitting. J. Am. Chem. Soc. 2017, 139, 3021-3026.

42. Ruan, Q.; Bayazit, M. K.; Kiran, V.; Xie, J.; Wang, Y.; Tang, J., Key factors affecting photoelectrochemical performance of $\mathrm{g}-\mathrm{C}_{3} \mathrm{~N}_{4}$ polymer films. Chem. Commun. 2019, 55, 7191-7194.

43. Huang, Y.; Wang, Y.; Bi, Y.; Jin, J.; Ehsan, M. F.; Fu, M.; He, T., Preparation of 2D hydroxyl-rich carbon nitride nanosheets for photocatalytic reduction of $\mathrm{CO}_{2}$. $R S C A d v$. 2015, 5, 33254-33261.

44. Niu, P.; Zhang, L.; Liu, G.; Cheng, H.-M., Graphene-Like Carbon Nitride Nanosheets for Improved Photocatalytic Activities. Adv. Funct. Mater. 2012, 22, 4763 4770 .

45. Elbanna, O.; Fujitsuka, M.; Majima, T., g- $\mathrm{C}_{3} \mathrm{~N}_{4} / \mathrm{TiO}_{2}$ Mesocrystals Composite for $\mathrm{H}_{2}$ Evolution under Visible-Light Irradiation and Its Charge Carrier Dynamics. ACS Appl. Mater. Inter. 2017, 9, 34844-34854.

46. Jiang, Q.; Zhao, Y.; Zhang, X.; Yang, X.; Chen, Y.; Chu, Z.; Ye, Q.; Li, X.; Yin, Z.; You, J., Surface passivation of perovskite film for efficient solar cells. Nat. Photon. 2019, 13, 460-466.

47. Qin, J.; Barrio, J.; Peng, G.; Tzadikov, J.; Abisdris, L.; Volokh, M.; Shalom, M., Direct growth of uniform carbon nitride layers with extended optical absorption towards efficient water-splitting photoanodes. Nat. Commun. 2020, 11, 4701.

48. Peng, G.; Albero, J.; Garcia, H.; Shalom, M., A Water-Splitting Carbon Nitride Photoelectrochemical Cell with Efficient Charge Separation and Remarkably Low Onset Potential. Angew. Chem. Int. Ed. 2018, 130, 16033-16037.

49. Ziebel, M. E.; Darago, L. E.; Long, J. R., Control of Electronic Structure and Conductivity in Two-Dimensional Metal-Semiquinoid Frameworks of Titanium, Vanadium, and Chromium. J. Am. Chem. Soc. 2018, 140, 3040-3051.

50. Che, Y.; Datar, A.; Yang, X.; Naddo, T.; Zhao, J.; Zang, L., Enhancing OneDimensional Charge Transport through Intermolecular $\pi$-Electron Delocalization: Conductivity Improvement for Organic Nanobelts. J. Am. Chem. Soc. 2007, 129, 63546355 .

51. Crispin, X.; Cornil, J.; Friedlein, R.; Okudaira, K. K.; Lemaur, V.; Crispin, A.; Kestemont, G.; Lehmann, M.; Fahlman, M.; Lazzaroni, R.; Geerts, Y.; Wendin, G.; Ueno, N.; Brédas, J.-L.; Salaneck, W. R., Electronic Delocalization in Discotic Liquid Crystals: A Joint Experimental and Theoretical Study. J. Am. Chem. Soc. 2004, 126, 11889-11899.

52. Lu, T., Multiwfn Manual, version 3.7(dev), Section 4.8.5, available at http://sobereva.com/multiwfn. 
53. Zhang, R.; Adsetts, J. R.; Nie, Y.; Sun, X.; Ding, Z., Electrochemiluminescence of nitrogen- and sulfur-doped graphene quantum dots. Carbon 2018, 129, 45-53.

54. Hesari, M.; Swanick, K. N.; Lu, J.-S.; Whyte, R.; Wang, S.; Ding, Z., Highly Efficient Dual-Color Electrochemiluminescence from BODIPY-Capped $\mathrm{PbS}$ Nanocrystals. J. Am. Chem. Soc. 2015, 137, 11266-11269.

55. Sivula, K., Mott-Schottky Analysis of Photoelectrodes: Sanity Checks Are Needed. ACS Energy Lett. 2021, 6, 2549-2551.

56. Peng, G.; Albero, J.; Garcia, H.; Shalom, M., A Water-Splitting Carbon Nitride Photoelectrochemical Cell with Efficient Charge Separation and Remarkably Low Onset Potential. Angew. Chem. Int. Ed. 2018, 57, 15807-15811.

57. Frisch, M. J.; Trucks, G. W.; Schlegel, H. B.; Scuseria, G. E.; Robb, M. A.; Cheeseman, J. R.; Scalmani, G.; Barone, V.; Petersson, G. A.; Nakatsuji, H.; Li, X.; Caricato, M.; Marenich, A. V.; Bloino, J.; Janesko, B. G.; Gomperts, R.; Mennucci, B.; Hratchian, H. P.; Ortiz, J. V.; Izmaylov, A. F.; Sonnenberg, J. L.; Williams; Ding, F.; Lipparini, F.; Egidi, F.; Goings, J.; Peng, B.; Petrone, A.; Henderson, T.; Ranasinghe, D.; Zakrzewski, V. G.; Gao, J.; Rega, N.; Zheng, G.; Liang, W.; Hada, M.; Ehara, M.; Toyota, K.; Fukuda, R.; Hasegawa, J.; Ishida, M.; Nakajima, T.; Honda, Y.; Kitao, O.; Nakai, H.; Vreven, T.; Throssell, K.; Montgomery Jr., J. A.; Peralta, J. E.; Ogliaro, F.; Bearpark, M. J.; Heyd, J. J.; Brothers, E. N.; Kudin, K. N.; Staroverov, V. N.; Keith, T. A.; Kobayashi, R.; Normand, J.; Raghavachari, K.; Rendell, A. P.; Burant, J. C.; Iyengar, S. S.; Tomasi, J.; Cossi, M.; Millam, J. M.; Klene, M.; Adamo, C.; Cammi, R.; Ochterski, J. W.; Martin, R. L.; Morokuma, K.; Farkas, O.; Foresman, J. B.; Fox, D. J. Gaussian 16 Rev. C.01, Wallingford, CT, 2016.

58. Lu, T.; Chen, F., Multiwfn: A multifunctional wavefunction analyzer. J. Comput. Chem. 2012, 33, 580-592. 